Sharif University of Technology
Scientia Iranica
SCIENTIA

Research Note

\title{
Risk-based switch placement in electric distribution network in the presence of performance-based regulation
}

\author{
M. Simab ${ }^{a}$ and A. Moradkhani ${ }^{b, *}$ \\ a. Department of Electrical Engineering, Marvdasht Branch, Islamic Azad University, Marvdasht, Iran. \\ b. Department of Electrical Engineering, Faculty of Engineering, Ilam University, Ilam, Iran.
}

Received 8 October 2018; received in revised form 4 April 2019; accepted 6 May 2019

\author{
KEYWORDS \\ Distribution networks \\ regulation; \\ Performance-based \\ regulation; \\ Power system \\ reliability; \\ Reward and penalty \\ scheme; \\ Switch placement.
}

\begin{abstract}
A Reward and Penalty Scheme (RPS) is generally used for setting up service quality and it will bring about financial benefits for distribution companies due to customer reliability and the resulting demand. In this paper, an algorithm was presented for the optimal switch number and placement in distribution networks in the presence of RPS. The main objective of this paper is to improve the reliability and minimize the costs of Sectionalizing Switches (SS) and Tie Switches (TS) for a given regulatory period considering the acceptable financial risk. In this algorithm, uncertainty in the reliability appears as a financial risk. A genetic algorithm was adopted to solve the optimization problem. The numbers and locations of SS and TS were determined by considering the financial incentives of RPS, capital investment and annual operation, and maintenance costs. The performance of the proposed approach was assessed and illustrated within a real distribution network. The results showed the efficiency of the proposed algorithm.
\end{abstract}

(C) 2021 Sharif University of Technology. All rights reserved.

\section{Introduction}

In recent years, regulators have made many attempts to create a competitive condition and allocate electricity distribution companies to the private sectors [1]. Natural monopoly of transmission and distribution activities are subject to economic regulations. The aim of regulation in restructured distribution networks is to improve the economic efficiency and quality of services and to protect customers against unreasonable tariffs on the services. Performance-Based Regulation (PBR), on the one hand, encourages cost efficiency and, on the other, suffers from lack of encouragement for

*. Corresponding author. Tel.: +98 8432227026

E-mail address: a.moradkhani@ilam.ac.ir (A. Moradkhani)

doi: $10.24200 /$ sci.2019.51470.2213 quality of service. Under this regulation, customers will receive services with lower quality than desired. This deficiency motivates the proposition of implementing Reward and Penalty Scheme (RPS) to guarantee the reliability of distribution companies. These incentives modify the revenues of companies according to their performance and penalize and reward companies with low and high quality, respectively [2]. In the presence of RPS and Distribution System Operators (DSOs) should make decisions in terms of whether to design the distribution network to improve or maintain the reliability of service [3]. Due to economic competition and deregulation, the risk of power outages would increase [4]. An effective way to improve reliability is to use Tie Switches (TS) and SS. Both the number and location of TS and SS should be optimized [5]. Numerous mathematical methods and intelligent algorithms have been proposed to ensure optimal switch placement 
including simulated annealing [6], Genetic Algorithms (GA) [7-10], Particle Swarm Optimization (PSO) [1113], ant colony search algorithm [14,15], and immune algorithm [16]. In [11], a novel three-state approach based on PSO was developed to determine the optimal number and locations of two types of switches in distribution systems. In [12], a Multi-Objective Switch Placement (MOSP) algorithm based on PSO was proposed to solve the problem of sectionalizing switch placement optimization in distribution networks. The proposed algorithm presents a set of solutions instead of a unique solution. A multi-objective planning scheme for allocating the Sectionalizing Switches (SS) and tie lines using PSO was investigated in [13]. In [17], a mixed-integer programming for sectionalizing the placement of switches through integrate switch malfunction probability was proposed. In [18], a new technique based on three operations was presented to solve the reconfiguration problem of distribution systems. A non-dominated sorting genetic algorithm II used for determining the number and location of remote controlled switches was presented in [19]. In this paper, the risk awareness of distribution companies was scrutinized via conditional value at risk. In [20], a Mixed-Integer Linear Programming (MILP) approach was proposed for determining the optimal number, type, and location of new automation devices and new locations of the existing devices. A method based on Micro-Genetic Algorithm (MGA) and Fuzzy Logic (FL) used for sectionalizing switch placement was proposed in [21]. In [22], a formulation was suggested for optimal placement of switches and reclosers in a distribution system under uncertainty in load data, system failure, and repair rates. In [5], an MILP approach was employed to solve the sectionalizing switch placement problem in the presence of Distributed Generation (DG). A method based on Harmony Search (HS) algorithm for optimal allocation of DG and recloser was suggested in [23]. In [24], a simple and effective model for the optimization problem was proposed to provide the optimal number, type, and position of switches to be installed each year so that both targeted annual reliability improvement and cheapest investment cost during the overall regulatory period would be achieved. First, DSOs choose the target level they would like to reach each year in the regulatory period and then, determine the related overall minimum investment cost to be paid for that target level. Due to the introduction of RPS to distribution networks, the significance of reliability has been considerably elevated for DSOs. In [24], the reliability of each year for a given regulatory period was considered as the objective function; however, the cost of RPS was not calculated.

In the proposed algorithm, RPS cost in the regulatory period was added to the capital investment, and the annual operation and maintenance costs of switches

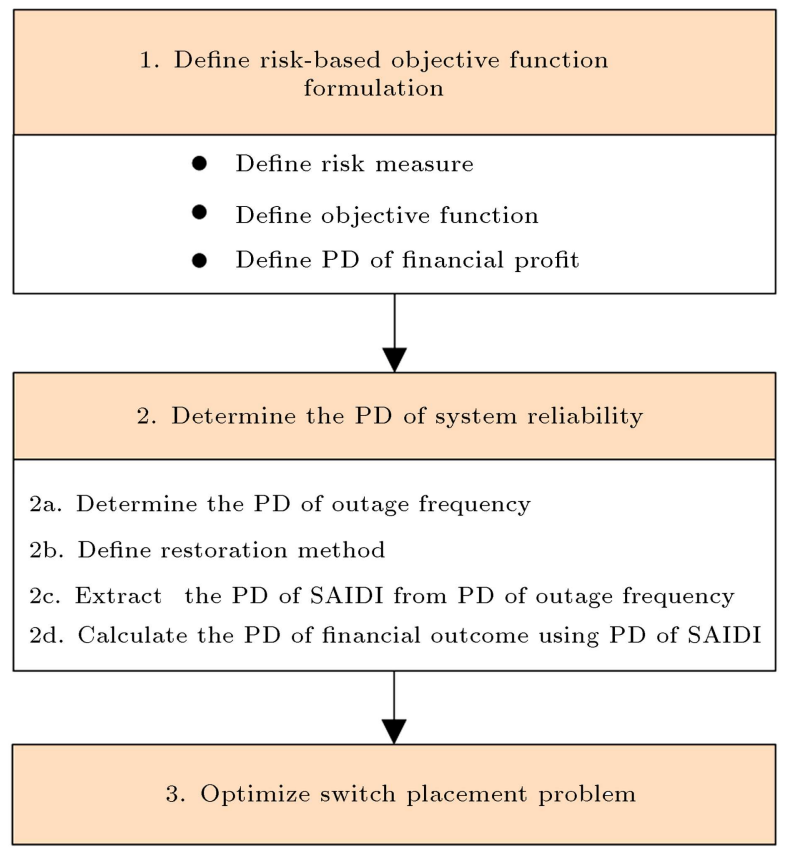

Figure 1. The steps of risk-based switch placement.

as well as the number and location of the switches were annually obtained in the regulatory period. In this algorithm, uncertainty in the reliability appeared as a financial risk. In fact, the main contribution of this paper is that it suggests a risk-based switch placement in the regulated distribution networks considering acceptable financial risk. This paper covers two topics in relation to the previous research. First, the switch placement problem was adopted with the RPS scheme and second, the risk-based formulation was incorporated to deal with the uncertainty that the DSO faced.

This section discusses the steps in applying the proposed risk-based switch placement model as shown in Figure 1. In the first step, the risk-based objective function is defined. In order to calculate the financial risk of placement of the switches, i.e., the Probability Distribution (PD) of financial outcome of installing a switch, it is required to calculate the uncertainty associated with system reliability, which is usually expressed using the PD of System Average Interruption Duration Index (SAIDI). To this end, this paper introduces an algorithm to determine the PD of outage frequency in step 2a and extracts the PD of SAIDI from the PD of outage frequency by applying restoration algorithm in steps $2 b$ and 2c. By considering the PD of SAIDI, the PD of financial outcome is calculated using step $2 \mathrm{~d}$ offers the optimal solution, i.e., the best switch placement plan, using GA.

This paper is organized as follows. Section 2 defines RPS. Section 3 presents the problem formulation. The obtained results are presented in Section 4. Section 5 concludes the study. 


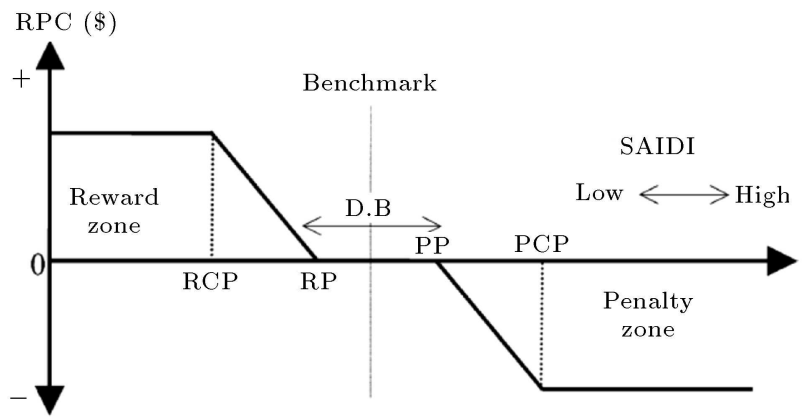

Figure 2. A general Reward and Penalty Scheme (RPS).

\section{Reward and Penalty Scheme (RPS)}

The reward-penalty schemes do not have a fixed structure in all conditions and can be modified when required [3]. Generally, RPS comprises three zones including: (a) the dead zone in which the company does not receive reward or penalty; (b) the reward zone in which the company is rewarded for quality improvement; and (c) the penalty zone in which the company is panelized for quality deterioration. Reliability indices are usually based on average customer interruption indices such as SAIFI (System Average Interruption Frequency Index) and SAIDI [25]. In this study, SAIDI was utilized as a reliability index. In case more than one reliability index should be included, a weighted RPS approach could be employed. In the weighted RPS approach, the RPS cost associated with each index is weighted based on the customer concern [2]. Figure 2 shows the general form of the RPS [21].

\section{Problem formulation}

The TS and SS are installed in order to increase the reliability of distribution networks. They are commonly used to improve reliability, isolate a fault, reconfigure it, and restore the network, thus reducing the interruption cost after a fault [14]. The appropriate allocation of switching devices is a key factor in reducing the restoration time and improving reliability index. Reliability performance is usually based on the average customer interruption indices such as SAIFI, SAIDI, and EENS (Expected Energy Not Supplied). In this paper, SAIDI and EENS were employed as the reliability indices. Figure 3 shows the flowchart of the proposed algorithm.

\subsection{Risk-based objective function formulation}

In stochastic optimization problems, the profit is a random variable usually expressed as a PD form. In an optimization problem, a function is required and specifies the $\mathrm{PD}$ of this random variable. To this end, the expected value of the profit was used in this study. Even though the expected value brings numerous advantages of describing the random vari-

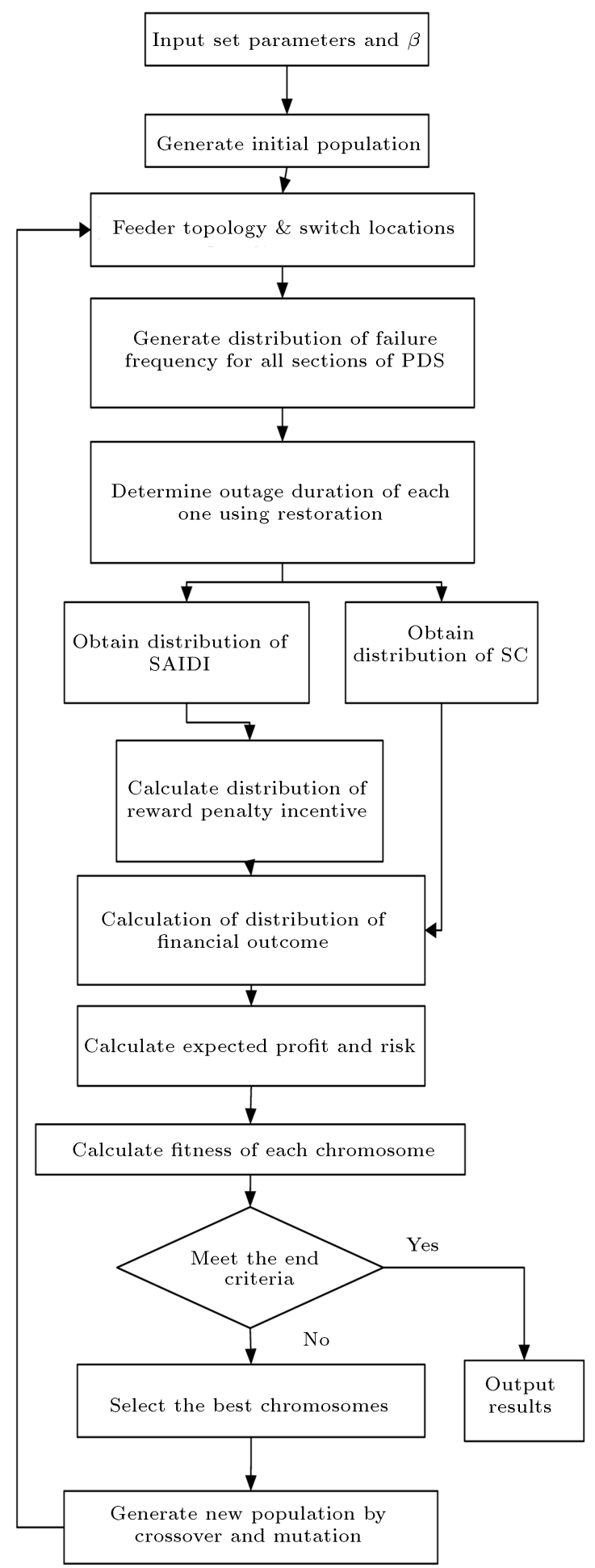

Figure 3. Flowchart of the proposed Sectionalizing Switches (SS) and Tie Switches (TS) placement.

able, it cannot determine other characteristics of the distribution associated with the random variable. For instance, it is very important for decision-makers that the risk of encountering a negative profit or loss, in addition to the expected amount of the acceptable profit, be shown by the random variable. Therefore, 
in order to control the risk of experiencing losses, it is necessary to consider a term for measuring the risk associated with a profit distribution. To this end, the Conditional Value-at-Risk (CVaR) index was used in this paper.

\subsubsection{Risk measure}

The Value at Risk (VaR) index is usually used to estimate a particular risk. This index measures the worst expected loss at a given confidence level $(1-\alpha) \%$. This index is expressed in the following:

$$
P\left[Z_{i} \leq \operatorname{VaR}_{\alpha}\right]=\alpha .
$$

The VaR index does not provide information about the worst potential losses which are beyond the confidence level. Therefore, in this paper, CVaR defined as the expected loss exceeding $\mathrm{VaR}$ is used. $C V a R$ of plan $i$ is expressed as follows:

$$
C V a R_{i}=E\left[Z_{i} \mid Z_{i}<\operatorname{VaR} R_{\alpha}\right]=\frac{\int_{-\infty}^{V a R_{\alpha}} Z_{i} f\left(Z_{i}\right) d Z_{i}}{P\left[Z_{i}<V a R_{\alpha}\right]}
$$

\subsubsection{Objective function}

The objective function for risk-based switch placement study is as follows:

$$
\max \left\{(1-\beta) \times \eta_{i}-\beta \times \chi_{i}\right\} .
$$

The $\eta_{i}$ and $\chi_{i}$ are formulated as follows:

$$
\begin{aligned}
& \eta_{i}=E\left[Z_{i}\right], \\
& \chi_{i}=C V a R_{i} .
\end{aligned}
$$

The factor $\beta \in[0,1]$ was used to model the risk aversion tendency of DSO in the objective function. The value of zero for $\beta$ shows that DSO is risk neutral and the value of one for this factor implies that the DSO is risk averse.

\subsubsection{Constraint}

The function problem should meet technical constraints including power demand and supply balance, maximum allowable voltage drops at load points, network radiality, and maximum feeder current limits.

\section{2. $P D$ of financial profit}

The PD of financial profit from installing SS and TS for the plan $i$ is given as follows:

$$
Z_{i}=\left(R P I_{i}-S C_{i}\right) .
$$

The $R P I_{i}$ is defined by:

$$
R P I_{i}=R P S(S A I D I) f_{i}(S A I D I),
$$

and it implies the reward/penalty incentive obtained from plan $i$.

The switch placement cost $\left(S C_{i}\right)$ of plan $i$ is mathematically expressed as follows:

$$
\begin{aligned}
S C_{i}= & \sum_{t=1}^{T}\left[\left(C C_{t}^{S S}+C C_{t}^{T S}\right)\left(\frac{D R(1+D R)^{m}}{D R(1+D R)^{m}-1}\right)\right. \\
& \left.(1+D R)^{-(t-1)}\right]+\sum_{t=1}^{T}\left[\left(M C_{t}^{S S}+M C_{t}^{T S}\right.\right. \\
& \left.\left.+f\left(C E N S_{t}\right)\right)(1+D R)^{-t}\right]
\end{aligned}
$$

\subsection{Determining the PD of system reliability}

In order to evaluate the reliability of each plan, the following algorithm was used:

Step 1: The suggested switches in the first year of each plan were applied to the network and then, the network was zoned so that every section placed between the two separating switches would form a zone;

Step 2: The distribution of outage frequencies during the first year with respect to the failure rate of each zone was calculated;

Step 3: Load restoration algorithm considering the fault occurring in each zone was performed and the interruption duration in all of the zones was calculated;

Step 4: The reliability indexes (ENS and SAIDI) were determined.

The uncertainty of the SAIDI index is mainly due to the uncertainty of outage duration and frequency. The outage duration is associated with the fault location and restoration time, which are assumed to be deterministic in this study where only the uncertainty caused by outage frequency was considered. PD of SAIDI is expressed as follows:

$$
\begin{aligned}
f(S A I D I)= & \frac{1}{N C_{T}} \sum_{t=1}^{T} \sum_{s=1}^{S} \sum_{z=1}^{Z_{s}} \\
& \left\{f\left(N_{t, s, z}\right) \sum_{k=1}^{Z_{s}}\left[D_{s, z, k} N C_{s, z}\right]\right\},
\end{aligned}
$$

$f\left(C E N S_{t}\right)$ is calculated based on the uncertainty of the ENS index as follows:

$$
\begin{aligned}
f\left(C E N S_{t}\right)= & \sum_{s=1}^{S} \sum_{z=1}^{Z_{s}}\left\{f\left(N_{t, s, z}\right)\right. \\
& \left.\sum_{k=1}^{Z_{s}} P_{N S, s, z} \sum_{l=1}^{4}\left[\alpha_{l, s, z} D_{s, z, k} \mathbb{C}_{l}\right]\right\} .
\end{aligned}
$$

As shown in Eqs. (9) and (10), it is necessary to calculate $f\left(N_{t, s, z}\right)$ to obtain both $f(S A I D I)$ and $f\left(C E N S_{t}\right)$. Therefore, an algorithm was proposed to 


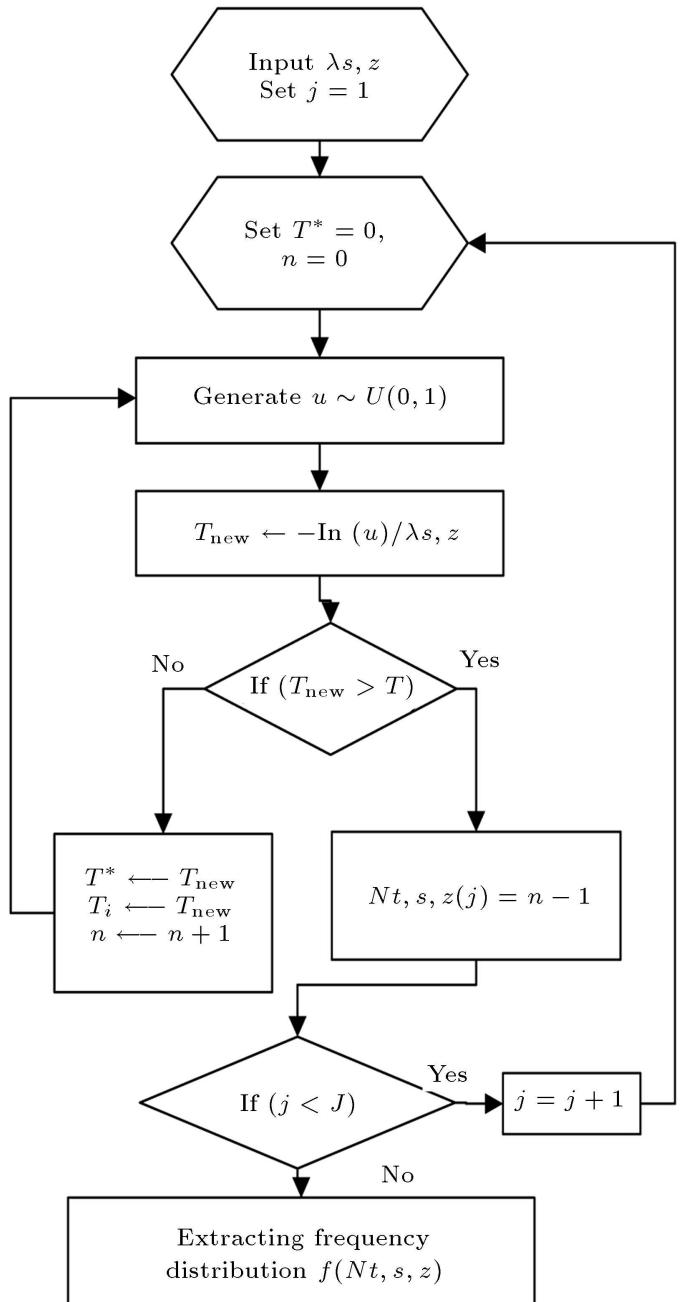

Figure 4. Flowchart of the algorithm for determining the outage frequency distribution.

extract $f\left(N_{t, s, z}\right)$ via the random generation method of failure times whose flowchart is shown in Figure 4.

By assuming a constant failure rate for section $z$ of feeder $s$, it can be concluded that this algorithm determines the number of failures of the intended section at the $[0, T]$ interval. By substituting the random number $u$ in Eq. (11), the time (s) of failure occurrence can be determined:

$$
T_{n e w}=-\ln (u) / \lambda_{s, z} .
$$

The occurrence times of the following failures can be determined in a similar fashion and the algorithm would continue its performance up until the occurrence time of the last failure after time $T$. Then, the failures occurring at the $[0, T]$ interval would be counted. If this algorithm is repeated enough, the frequency distribution of the desired zone will be achieved.

\subsubsection{Restoration method}

When a fault occurs in a given zone of network, the outage time of customers will be obtained as follows [3]: a. Customers located downstream of the faulty zone: The outage time and the repair time are equal if no TS and back up services are available. However, if they exist, the outage time is equal to the time required for switching;

b. Customers located upstream the faulty zone: The outage time of these customers and switching time are equal;

c. Customers located in the faulty zone: The outage time and repair time are equal.

In order to determine the above-mentioned outage times, a restoration algorithm was proposed based on fundamental cut-set concept in the graph theory.

Finding fundamental cut-set of downstream of faulty zone: Distribution network can be considered as a rooted spanning tree $T$ of a graph $G=(V, E)$. $T$ can be changed to another tree by opening a line $e$ of $T$ and closing a non-tree line $m \in E-T$ on condition that $m$ is a fundamental cut-set of $e$. Similarly, a distribution network can be restored by opening the SS of the faulted zone downstream and closing TS if the latter is the fundamental cut-set of SS. By identifying the fundamental cut-set, the unfeasible configurations can be avoided in the restoration process. To find the fundamental cut-set of node $v$, all nodes of the distribution network must be numbered using the preorder method [26]. Therefore, pre $(v)$ is the pre-order number of node $v$ and $\operatorname{dow} s(v)$ presents the number of downstream nodes of $v$. In addition, $a(v)$ denotes the quantity pre $(v)+\operatorname{dows}(v)$ [27]. Considering the definition of the pre-order numbering, any downstream node $w$ of $v$ had a pre-order number greater than $\operatorname{pre}(v)$, yet not more than $a(v)$, as shown in the following:

$$
\operatorname{pre}(v)<\operatorname{pre}(w) \leq \operatorname{pre}(v)+\operatorname{dows}(v) .
$$

In addition, any non-downstream node of $v$ has a preorder number which is either less than pre $(v)$ or greater than $a(v)$. The fundamental cut-sets of $v$ can be defined as a set of $E_{1}(v) \cup E_{2}(v)$, as defined below:

$$
\begin{aligned}
E_{1}(v)= & \{(b, c): 1 \leq \operatorname{pre}(b)<\operatorname{pre}(v) \\
& \text { and }(b, c) \in E-T\}, \\
E_{2}(v)= & \{(b, c): \operatorname{pre}(v) \leq \operatorname{pre}(b) \leq a(v) \\
& \text { and }(b, c) \in E-T\} .
\end{aligned}
$$

Restoration algorithm: Upon considering faults in the zone $z$ of feeder $s$, the following steps are taken in the restoration process: 
Step 1: Apply the isolation process by opening the upstream and downstream switches closest to the faulty section;

Step 2: Find the upstream zones, faulty zones, and downstream zones of the faulty section. The loads of the upstream zones are restored after switching time and the interruption duration of the load of faulty zone is equal to the repairing time;

Step 3: Determine all fundamental cut-sets (TS) of its root node and sort them based on their available transfer capability $\left\{T S_{1}, \cdots, T S_{i}\right\}$ for any zone at downstream of faulty zone;

Step 4: Open all SS's downstream of the faulty zone and set $i=1$;

Step 5: Set $k=1$; close $T S_{i} \forall i=1,2, \cdots, I$, and sort all open switches $S S_{k} \forall k=1,2, \ldots, K$ based on their adjacency to $T S_{i}$; then, check for any violation of constraints via load flow analysis;

Step 6: If violation occurs, set $i=i+1$ and go to Step 5;

Step 7: Otherwise, close the adjacent $S S_{k} \forall k=$ $1,2, \ldots, K$ and check for any violation of constraints by load flow analysis;

Step 8: In case of the violation, store the switch operation set open $S S_{k}$, close $T S_{i}$ and assign the zones in the pass between $T S_{i}$ and $S S_{k}$ as the restored zone; otherwise, set $k=k+1$ and go to Step 7;

Step 9: If all downstream zones are restored, store the switch operation close $T S_{i}$ and go to Step 12;

Step 10: Otherwise, if $k<K$ and $i<I$, update $K$ based on the number of the remaining SS's downstream of the faulty zone; set $i=i+1$ and go to Step 5;

Step 11: Specify the switch operation pairs, i.e., restored and unrestored zones;

Step 12: Calculate the restoration time for the restored zones.

The restoration algorithm flowchart is shown in Figure 5 .

\subsection{Finding an optimal solution using $G A$}

In this paper, a GA was presented for optimal number, type, and position of the switches in a regulated distribution network. A chromosome was specified by $N \times 2$ matrix, where $N$ denotes the number of candidate locations of SS and TS. Each row shows a binary number and its equivalent to the decimal number indicates the year of installation, as shown in Figure 6.

\section{Numerical results}

The proposed method was applied to the real 172-bus power distribution system of Ilam Power Distribution Company (IPDC). This network comprises 7 feeders and 3 TS, as shown in Figure 7 . In this network, 25 candidate locations for installing the SS and 6 candidate locations for installing the TS are suggested in Table 1. The investment cost of SS is 4700 and the cost of line is assumed $7000 \$ / \mathrm{km}$. The annual maintenance cost is $2 \%$ of the investment cost, the life cycle of the switches is 15 years, the load growth rate is $3 \%$, and the interest rate is $8 \%$ [28]. The price of undelivered energy during outages is shown in Table 2 and RPS parameters are given in Table 3 . The regulatory period is three years. For GA application, the parameters were selected, as shown in Table 4 . In this paper, MATLAB coding was developed to validate

Table 1. Candidate locations of Tie Switches (TS).

\begin{tabular}{ccc}
\hline TS candidates & From bus & To bus \\
\hline T1 & 133 & 152 \\
T2 & 17 & 40 \\
T3 & 91 & 118 \\
T4 & 104 & 145 \\
T5 & 7 & 68 \\
T6 & 52 & 120 \\
\hline
\end{tabular}

Table 2. The value of energy for different customer types.

\begin{tabular}{cc}
\hline Category & $\begin{array}{c}\text { Value of energy } \\
(\$ \mathbf{k W h})\end{array}$ \\
\hline Residential & 0.05 \\
Commercial & 0.2 \\
Industrial & 0.2 \\
Institution & 0.14 \\
\hline
\end{tabular}

Table 3. Input values of Reward and Penalty Scheme (RPS) parameters for System Average Interruption Duration Index (SAIDI).

\begin{tabular}{ccccc}
\hline RCP & RP & PP & PCP & $\begin{array}{c}\text { Incentive rate } \\
(\mathbf{1 0 0 0} \$ \mathbf{m i n})\end{array}$ \\
\hline 227 & 315 & 473 & 553 & 0.375 \\
\hline
\end{tabular}

Table 4. Genetic algorithm parameters.

\begin{tabular}{cc}
\hline Parameters & Values \\
\hline Number of iterations & 200 \\
Population size & 40 \\
Mutation probability & 0.02 \\
Crossover probability & 0.8 \\
Chromosome length & $31 \times 2$ binary genes \\
\hline
\end{tabular}




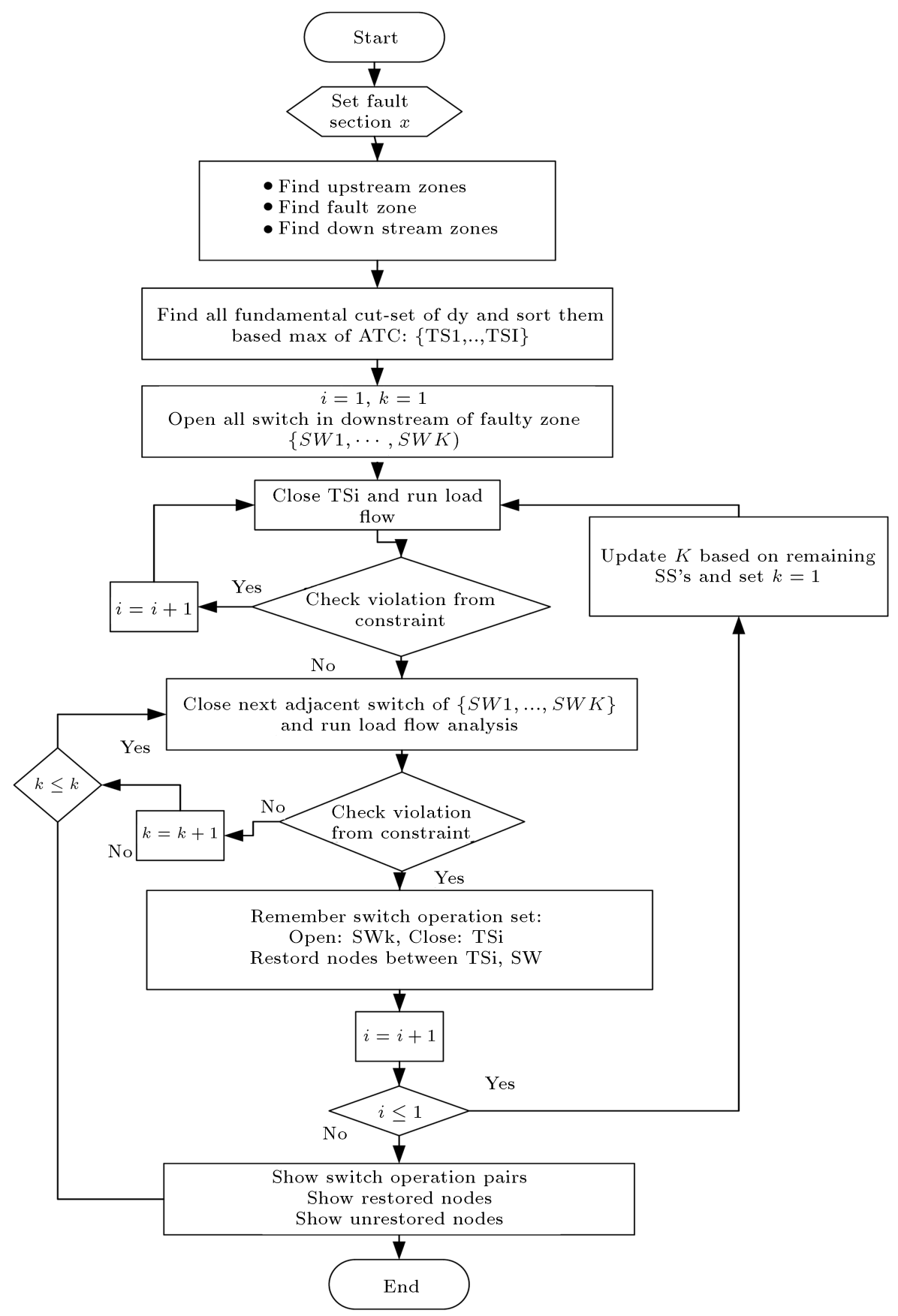

Figure 5. Flowchart of the restoration algorithm.

the proposed algorithm. The algorithm presented in this paper was investigated in four different case studies:

Case 1: (Base case) Current distribution network (before installing any switches in the system);

Case 2: Optimal sectionalizing switch placement using the proposed algorithm;

Case 3: Optimal sectionalizing switch placement regardless of RPS cost;
Case 4: Optimal sectionalizing switch placement considering the budget limitations.

In Case 1 (base case), two switches are located at locations 43 and 156 . In case of no investment in the installation of other switches, at the end of the third year, the profit of the company and the losses beyond VaR expectation would be $\$-56771$ and $\$ 97948$, respectively, based on the simulation results. Moreover, the expected value of SAIDI index in this network is equal to 401.4 minutes. 


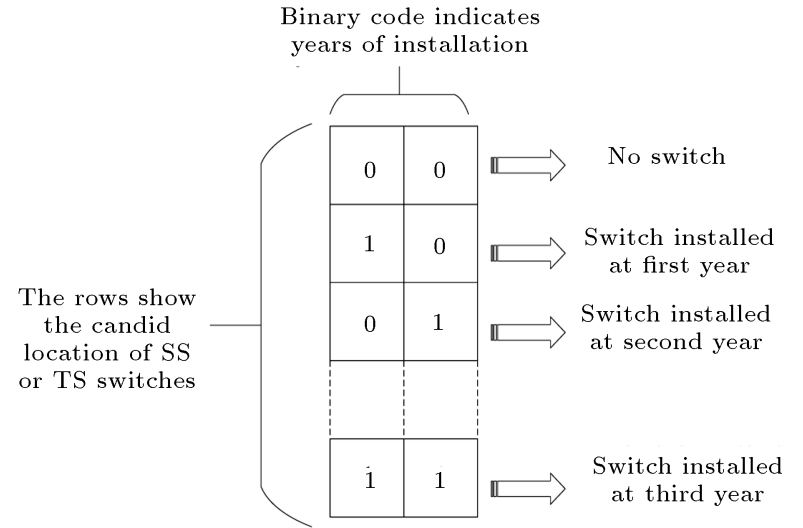

Figure 6. Chromosome structure.

Table 5 shows the results of optiomal SS and TS in Case 2 using the proposed algorithm. The results show that if the company is risk neutral $(\beta=0)$, using 11 SS and 2 TS can have a profit equal to $\$-6080$ at the end of the third year, which can be improved to about $\$ 50691$ compared to the base case. The optimum number of the switches for each year and their locations are given in Table 5. In this case, the risk index (CVaR or expected shortfall) is $\$ .24715$ It is implied that the expected loss at a confidence level of $95 \%$ is $\$ 24715$, which has a reduction value of $\$ 73233$ in comparison with the base case. The expected value of the SAIDI index in this case is reduced by $43.3 \%$ compared to that in the base case and it has reached 227.5 minutes.

According to the switch placement results, if the company is risk neutral due to installing fewer switches (11 SS and 2 TS), a higher expected profit would be ensured. On the other hand, there is the risk of probable higher loss. Given that the company grows by being risk averse, the number of the installed switches would be increased. For instance, if $0.1 \leq \beta \leq 0.2$, according to Table 5, the optimal number of switches includes $12 \mathrm{SS}$ and $2 \mathrm{TS}$. If the company is completely risk averse $\beta=1$, then the investment must be increased and $13 \mathrm{SS}$ and 2 TS must be installed. In this case, the risk index and the expected profit of the company are reduced to $\$ 19549$ and $\$-6794$, respectively. The increase of switch installations will lead to a reduction in the expected profit of the company. The location of

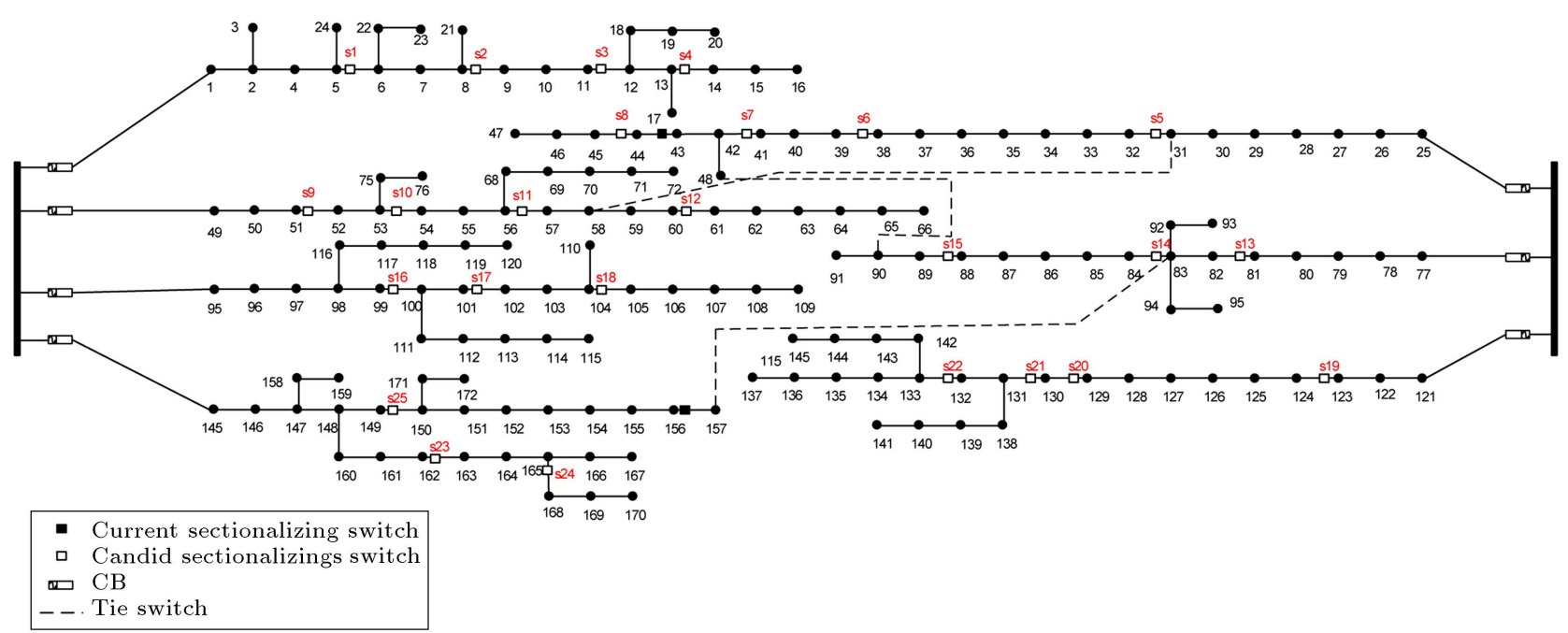

Figure 7. Single-line diagram of the real 172-bus power distribution system.

Table 5. Optimal sectionalizing switch placement using the proposed algorithm.

\begin{tabular}{|c|c|c|c|c|c|c|c|}
\hline$\beta$ & Year & New switches locations & $\eta_{i}(\$)$ & $\chi_{i}(\$)$ & $S C(\$)$ & RPI (\$) & $\begin{array}{c}E \text { (SAIDI) } \\
(\min )\end{array}$ \\
\hline \multirow{3}{*}{$\beta=0$} & 1 & $\mathrm{~S} 3, \mathrm{~S} 5, \mathrm{~S} 10, \mathrm{~S} 16, \mathrm{~S} 17, \mathrm{~S} 20, \mathrm{~S} 25, \mathrm{~T} 2, \mathrm{~T} 4$ & & & & & \\
\hline & 2 & $\mathrm{~S} 11, \mathrm{~S} 13$ & -6080 & 24715 & 53242 & 47162 & 227.5 \\
\hline & 3 & $\mathrm{~S} 14, \mathrm{~S} 19$ & & & & & \\
\hline \multirow{3}{*}{$0.1 \leq \beta \leq 0.2$} & 1 & $\mathrm{~S} 3, \mathrm{~S} 5, \mathrm{~S} 10, \mathrm{~S} 11, \mathrm{~S} 13, \mathrm{~S} 14, \mathrm{~S} 20, \mathrm{~S} 25, \mathrm{~T} 2, \mathrm{~T} 4$ & & & & & \\
\hline & 2 & $\mathrm{~S} 17, \mathrm{~S} 19$ & -6387 & 20931 & 54643 & 48256 & 221.3 \\
\hline & 3 & $\mathrm{~S} 6, \mathrm{~S} 8$ & & & & & \\
\hline \multirow{3}{*}{$0.3 \leq \beta \leq 1$} & 1 & $\mathrm{~S} 2, \mathrm{~S} 6, \mathrm{~S} 10, \mathrm{~S} 11, \mathrm{~S} 13, \mathrm{~S} 16, \mathrm{~S} 19, \mathrm{~S} 20, \mathrm{~S} 25, \mathrm{~T} 2, \mathrm{~T} 4$ & & & & & \\
\hline & 2 & S5, S17 & -6794 & 19549 & 55339 & 48544 & 213.8 \\
\hline & 3 & $\mathrm{~S} 3, \mathrm{~S} 14$ & & & & & \\
\hline
\end{tabular}


Table 6. Optimal sectionalizing switch placement regardless of Reward and Penalty Scheme (RPS) cost.

\begin{tabular}{cccccccc}
\hline $\boldsymbol{\beta}$ & Year & New switches locations & $\boldsymbol{\eta}_{\boldsymbol{i}}(\$)$ & $\boldsymbol{\chi}_{\boldsymbol{i}}(\$)$ & $\boldsymbol{S C}(\$)$ & $\mathbf{R P I}(\$)$ & $\begin{array}{c}\boldsymbol{E} \text { (SAIDI) } \\
(\mathbf{m i n})\end{array}$ \\
\hline \multirow{2}{*}{1} & $\mathrm{~S} 5, \mathrm{~S} 11, \mathrm{~S} 25$ & & & & & \\
& 2 & $\mathrm{~S} 13$ & -47085 & 58332 & 47085 & 0 & 332.6 \\
& 3 & $\mathrm{~S} 3, \mathrm{~T} 2$ & & & & & \\
$0.2 \leq \beta \leq 1$ & 1 & $\mathrm{~S} 5, \mathrm{~S} 25$ & & & & & \\
& 2 & $\mathrm{~S} 11$ & -47494 & 57976 & 47494 & 0 & \\
\hline
\end{tabular}

Table 7. Optimal sectionalizing switch placement regarding budget limitations.

\begin{tabular}{cccccccc}
\hline $\boldsymbol{\beta}$ & Year & New switches locations & $\boldsymbol{\eta}_{\boldsymbol{i}}(\$)$ & $\chi_{\boldsymbol{i}}(\$)$ & $\boldsymbol{S C}(\$)$ & $(\$)$ & $\begin{array}{c}\boldsymbol{E} \text { (SAIDI) } \\
(\mathbf{m i n})\end{array}$ \\
\hline \multirow{3}{*}{$0 \leq \beta \leq 0.1$} & 2 & $\mathrm{~S} 5, \mathrm{~S} 11, \mathrm{~S} 13, \mathrm{~S} 16, \mathrm{~S} 20, \mathrm{~S} 25$ & & & & & \\
& 3 & $\mathrm{~S} 6, \mathrm{~S} 10, \mathrm{~S} 19, \mathrm{~T} 2, \mathrm{~T} 14, \mathrm{~S} 17, \mathrm{~S} 24$ & -9162 & 40540 & 52902 & 43740 & 246.8 \\
& & & & & & \\
$0.2 \leq \beta \leq 1$ & 2 & $\mathrm{~S} 2, \mathrm{~S} 5, \mathrm{~S} 13, \mathrm{~S} 25, \mathrm{~T} 2$ & & & & & \\
& 3 & $\mathrm{~S} 11, \mathrm{~S} 16, \mathrm{~S} 19, \mathrm{~S} 20, \mathrm{~T} 4$ & -9372 & 38728 & 53082 & 43707 & 249.6 \\
\hline
\end{tabular}

the SS in different scenarios will be different; however, in all of the scenarios, there are only two TS for the two feeders with no TS.

Table 6 shows the results of optimal SS regardless of the RPS cost in the regulatory period. The results of the simulation indicate that in this case, the number of optimum switches will be reduced in comparison with Case 2. In this case, if the company is risk neutral, then the optimum number of the SS will be 5 , the optimum number of the TS 1 , the risk index $\$ 58332$, and the expected profit of the company $-\$ 47085$. The expected value of SAIDI in this case is $17.1 \%$ and it has been reduced in comparison to the base case and is increased by $46.2 \%$ in comparison with Case 2. According to the results, by considering RPS, the company will find a financial incentive for improving the reliability. In Case 2 , the company will receive $\$ 47162$ for RPS, which covers the switch placement cost. Comparison of the results shown in Table 5 and those in Table 6 indicates the role of RPS in improving the reliability.

The results in Table 5 show that due to budget limitations, installation of the switches is mostly considered in the first year. In Case 4, the investment limitation is assumed $\$ 30000$. The results of this simulation are given in Table 7 . The results in Table 7 show that if a company is risk neutral, then the optimum number of the SS is 13 , the optimum number of the TS is 2 , the risk index is $\$ 40540$, and the expected profit of the company is $-\$ 9162$. In this case,

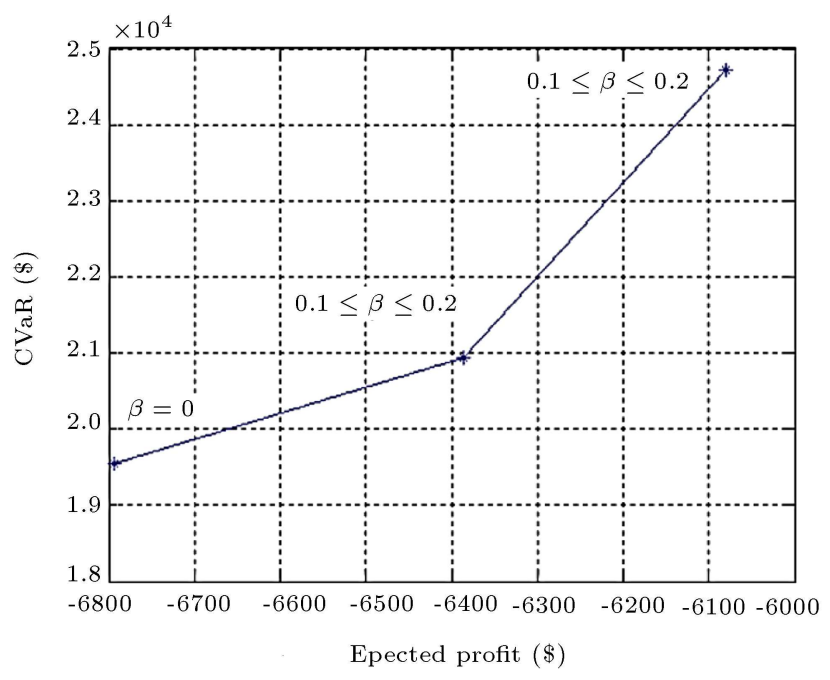

Figure 8. Efficient frontier of Distribution System Operator (DSO) in switch placement.

due to the investment limitations, the number of the considered switches has increased in the second and third years. The expected value of SAIDI in this case has increased by $8.5 \%$ compared to Case 2 .

The collection of optimal solutions for Case 2 in terms of expected profit and risk defines an efficient frontier (Figure 8). Efficient frontiers are appropriate tools for decision-makers to evaluate the trade-off between expected profit and risk. It can be observed that a small value of $\beta$ yields a plan with high expected 
Table 8. Optimal sectionalizing switch placement using the Particle Swarm Optimization (PSO) algorithm.

\begin{tabular}{|c|c|c|c|c|c|c|c|}
\hline $\boldsymbol{\beta}$ & Year & New switches locations & $\eta_{i}(\$)$ & $\chi_{i}(\$)$ & $S C(\$)$ & RPI (\$) & $\begin{array}{c}E(\text { SAIDI }) \\
(\min )\end{array}$ \\
\hline \multirow{3}{*}{$\beta=0$} & 1 & $\mathrm{~S} 3, \mathrm{~S} 6, \mathrm{~S} 10, \mathrm{~S} 16, \mathrm{~S} 17, \mathrm{~S} 20, \mathrm{~S} 25, \mathrm{~T} 2, \mathrm{~T} 4$ & & & & & \\
\hline & 2 & $\mathrm{~S} 11, \mathrm{~S} 13$ & -6157 & 24604 & 53393 & 47236 & 227.9 \\
\hline & 3 & $\mathrm{~S} 6, \mathrm{~S} 15$ & & & & & \\
\hline \multirow{3}{*}{$0.1 \leq \beta \leq 0.2$} & 1 & $\mathrm{~S} 3, \mathrm{~S} 5, \mathrm{~S} 10, \mathrm{~S} 11, \mathrm{~S} 13, \mathrm{~S} 14, \mathrm{~S} 20, \mathrm{~S} 25, \mathrm{~T} 2, \mathrm{~T} 4$ & & & & & \\
\hline & 2 & $\mathrm{~S} 17, \mathrm{~S} 19$ & -6387 & 20931 & 54643 & 48256 & 221.3 \\
\hline & 3 & S6, S8 & & & & & \\
\hline \multirow{3}{*}{$0.3 \leq \beta \leq 1$} & 1 & $\mathrm{~S} 2, \mathrm{~S} 5, \mathrm{~S} 10, \mathrm{~S} 11, \mathrm{~S} 14, \mathrm{~S} 16, \mathrm{~S} 19, \mathrm{~S} 20, \mathrm{~S} 25, \mathrm{~T} 2, \mathrm{~T} 4$ & & & & & \\
\hline & 2 & $\mathrm{~S} 6, \mathrm{~S} 17$ & -6811 & 19755 & 55431 & 48620 & 215.4 \\
\hline & 3 & $\mathrm{~S} 3, \mathrm{~S} 13$ & & & & & \\
\hline
\end{tabular}

profit and high risk. Besides, a large value of $\beta$ attains a plan with lower expected profit and lower risk.

In this paper, four crossover and mutation strategies used in different pieces of literature were tested. The results of the optimization of each mutation strategy were compared and the best answer was selected. Due to limited space, we cannot insert all tables in this paper. Moreover, the optimal answer during the 30 trial runs was chosen and each run consisted of 200 iterations. To demonstrate the superiority of the proposed algorithm, the results obtained from GA were compared with well-established PSO algorithm. Table 8 shows the results of optimal SS and TS in Case 2 using the PSO algorithm. Based on the results, the GA presented better results for $\beta=0$ and $0.3 \leq$ $\beta \leq 1$.

\section{Conclusion}

In the presence of Performance-Based Regulation (PBR), the distribution companies must set up reliability enhancement programs in order not to face penalties at the end of the fiscal period and use bonus benefits as much as they can. In this paper, a riskbased method was proposed for both sectionalizing and tie switches in the presence of Reward and Penalty Scheme (RPS). In this respect, the main objective of this study was to optimize the reliability level and minimize the costs calculated by genetic algorithm. The proposed algorithm was capable of obtaining the optimum number and location of both sectionalizing and tie switches in the regulatory period by determining a proper risk level. CVaR was regarded as the indicator of the expected loss value and it was greater than the value at risk used as the risk index in this paper. The proposed method was applied to a real distribution network, the results of which were reported for a regulatory period of three years. This paper also pointed to the impacts of RPS cost in the regulatory period on the optimum number and location of the switches and network reliability. In case the company was not bound to any annual budget limitations, it could choose optimal sectionalizing switch placement by considering any desired risk level. The results showed that if the company was risk averse, more switches should be installed and the expected profit of the company would consequently decrease. However, if more profit was desired, the switch installation might cost less; however, a higher risk would be inevitable.

\section{Nomenclature}

$C C_{t}^{S S} \quad$ Capital investment and installation cost of SS installed in year $t$

$C C_{t}^{T S}$

$\mathbb{C}_{l}$

$D_{s, z, k}$

Capital investment and installation cost of TS installed in year $t$ interruption due to failure occurrence in the $z$-th zone of the $s$-th feeder

$D R \quad$ Annual discount rate

$f_{i}(S A I D I)$ Probability distribution of SAIDI for plan $i$

$f\left(C E N S_{t}\right) \quad$ Probability distribution of cost of energy not supplied in year $t$

$f\left(N_{t, s, z}\right) \quad$ Frequency distribution of failures in the $z$-th zone of the $s$-th feeder in year $t$

$M C_{t}^{S S} \quad$ Operation and maintenance cost of SS in year $t$

$M C_{t}^{T S} \quad$ Operation and maintenance cost of TS in year $t$

$m \quad$ Life cycle of SS and TS 
$N C_{T} \quad$ Total number of customers

$N C_{s, z} \quad$ Number of customers located in the $z$-th zone of the $s$-th feeder

$P_{N S, s, z} \quad$ Expected interrupted load $(\mathrm{kW})$ in the $z$-th zone of the $s$-th feeder

$R P I_{i} \quad$ Probability distribution of reward penalty incentive for plan $i$

RPS(SAIDI) Reward Penalty Scheme based on SAIDI index

$S C_{i} \quad$ Cost of switch placement for plan $i$

$T \quad$ Period of regulation

$\operatorname{VaR}_{\alpha} \quad$ Value at risk at a given confidence level $(1-\alpha) \%$

$Z_{i} \quad$ Financial outcome of plan $i$

$Z_{s} \quad$ Number of zones in the $s$-th feeder

$\alpha_{l, s, z} \quad$ Contribution percentage of load sector

$l$ in zone $z$ of feeder $s$

$\eta_{i}$

Expected profit of plan $i$

$\chi_{i} \quad$ Risk of plan $i$

$K, I \quad$ Number of the SS's and TS's downstream of a faulty zone

\section{References}

1. Simab, M. and Haghifam, M.-R. "Using integrated model to assess the efficiency of electric distribution companies", IEEE Transactions on Power Systems, 25(4), pp. 1806-1814 (2010).

2. Simab, M., Alvehag, K., Sider, L., et al. "Designing reward and penalty scheme in performance-based regulation for electric distribution companies", IET Generation, Transmission \& Distribution, 6(9), pp. 893-901 (2012).

3. Moradkhani, A., Haghifam, M.R., and Abedi, S.M. "Risk-based maintenance scheduling in the presence of reward penalty scheme", Electric Power Systems Research, 121, pp. 126-133 (2015).

4. Ketabi, A., Ranjbar, A., and Feuillet, R. "A new method for load steps calculation during power system restoration", Scientia Iranica, 9(4), pp. 328-335 (2003).

5. Heidari, A., Agelidis, V.G., and Kia, M. "Considerations of sectionalizing switches in distribution networks with distributed generation", IEEE Transactions on Power Delivery, 30(3), pp. 1401-1409 (2015).

6. Billinton, R. and Jonnavithula, S. "Optimal switching device placement in radial distribution systems", IEEE Transactions on Power Delivery, 11(3), pp. 1646-1651 (1996).

7. Haghifam, M.R. "Optimal allocation of tie points in radial distribution systems using a genetic algorithm", European Transactions on Electrical Power, 14(2), pp. 85-96 (2004).
8. Levitin, G., Mazal-Tov, S., and Elmakis, D. "Genetic algorithm for optimal sectionalizing in radial distribution systems with alternative supply", Electric Power Systems Research, 35(3), pp. 149-155 (1995).

9. Dezaki, H., Abyaneh, H., Agheli, A., et al. "Optimized switch allocation toi mprove the restoration energy in distribution systems", Journal of Electrical Engineering, 63(1), pp. 47-52 (2012).

10. Pombo, A.V., Murta-Pina, J., and Pires, V.F. "A multiobjective placement of switching devices in distribution networks incorporating distributed energy resources", Electric Power Systems Research, 130, pp. 34-45 (2016).

11. Moradi, A. and Fotuhi-Firuzabad, M. "Optimal switch placement in distribution systems using trinary particle swarm optimization algorithm", IEEE Transactions on Power Delivery, 23 (1), pp. 271-279 (2008).

12. Bezerra, J.R., Barroso, G.C., Leão, R.P.S., et al. "Multiobjective optimization algorithm for switch placement in radial power distribution networks", IEEE Transactions on Power Delivery, 30(2), pp. 545-552 (2015).

13. Sahoo, N., Ganguly, S., and Das, D. "Multi-objective planning of electrical distribution systems incorporating sectionalizing switches and tie-lines using particle swarm optimization", Swarm and Evolutionary Computation, 3, pp. 15-32 (2012).

14. Teng, J.-H. and Liu, Y.-H. "A novel ACS-based optimum switch relocation method", IEEE Transactions on Power Systems, 18(1), pp. 113-120 (2003).

15. Falaghi, H., Haghifam, M.-R., and Singh, C. "Ant colony optimization-based method for placement of sectionalizing switches in distribution networks using a fuzzy multiobjective approach", IEEE Transactions on Power Delivery, 24(1), pp. 268-276 (2009).

16. Chen, C.-S., Lin, C.-H., Chuang, H.-J., et al. "Optimal placement of line switches for distribution automation systems using immune algorithm", IEEE Transactions on Power Systems, 21(3), pp. 1209-1217 (2006).

17. Farajollahi, M., Fotuhi-Firuzabad, M., and Safdarian, A. "Optimal placement of sectionalizing switch considering switch malfunction probability", IEEE Transactions on Smart Grid, 10(1), pp. 403-413 (2019).

18. Abazari, S. and Soudejani, M.H. "A new technique for efficient reconfiguration of distribution networks", Scientia Iranica, Transaction, D, Computer Science \& Engineering, Electrical, 22(6), p. 2516 (2015).

19. Izadi, M. and Safdarian, A. "Financial risk constrained remote controlled switch deployment in distribution networks", IET Generation, Transmission \& Distribution, 12(7), pp. 1547-1553 (2017).

20. Popović, Ц̆., Brbaklić, B., and Knežević, S. "A mixed integer linear programming based approach for optimal placement of different types of automation devices in distribution networks", Electric Power Systems Research, 148, pp. 136-146 (2017). 
21. do Nascimento Alves, H. "A hybrid application based on expert knowledge for solving the switches placement problem in distribution networks", Journal of Control, Automation and Electrical Systems, 25(2), pp. 252-261 (2014).

22. Alam, A., Pant, V., and Das, B. "Switch and recloser placement in distribution system considering uncertainties in loads, failure rates and repair rates", Electric Power Systems Research, 140, pp. 619-630 (2016).

23. Morsali, R., Ghadimi, N., Karimi, M., et al. "Solving a novel multiobjective placement problem of recloser and distributed generation sources in simultaneous mode by improved harmony search algorithm", Complexity, 21(1), pp. 328-339 (2015).

24. Conti, S., Rizzo, S.A., and Zeineldin, H.H. "Optimal switch placement considering costs and annual reliability improvement during the regulatory period", International Transactions on Electrical Energy Systems, 27(5), e2309, pp. 1-14 (2016). DOI: 10.1002/etep.2309

25. Brown, R.E. and Burke, J.J. "Managing the risk of performance based rates", IEEE Transactions on Power Systems, 15(2), pp. 893-898 (2000).

26. Saxena, S. "On finding fundamental cut sets", Information Processing Letters, 110(4), pp. 168-170 (2010).

27. Aho, A., Hopcroft, J., and Ullman, J., Design and Analysis of Computer Algorithms, Addison-Wesley, 1st Ed. (1974).
28. Abiri-Jahromi, A., Fotuhi-Firuzabad, M., Parvania, M., et al. "Optimized sectionalizing switch placement strategy in distribution systems", IEEE Transactions on Power Delivery, 27(1), pp. 362-370 (2012).

\section{Biographies}

Mohsen Simab received his BSc degree in Electrical Engineering from Amir Kabir University, Tehran, Iran in 2003 and obtained the MSc and PhD degrees from Tarbiat Modares University, Tehran, Iran, 2005, and 2011, respectively. He is currently an Assistant Professor in Power Systems at the Department of Electrical Engineering, Marvdasht Branch, Islamic Azad University, Marvdasht, Iran. His main research interests are electric distribution regulation, power system operation, and power system reliability.

Amin Moradkhani was born in Abdanan, Iran in 1981. He received his BSc degree in Electrical Engineering from the University of Amir Kabir, Tehran, Iran in 2004 and obtained the MSc and $\mathrm{PhD}$ degrees in the same field of study from the Tarbiat Modares University, Tehran, Iran in 2006 and 2014, respectively. In 2014, he joined the Department of Electrical Engineering, University of Ilam as an Assistant Professor. His current research interests include planning and operation of power distribution system, reliability, and smart grid. 